\title{
Electrical Power Grid Delivery Dynamic Analysis: Using Prime Mover Engines to Balance Dynamic Wind Turbine Output
}

\section{IMECE 2011}

\section{Diana K. Grauer}

Michael E. Reed

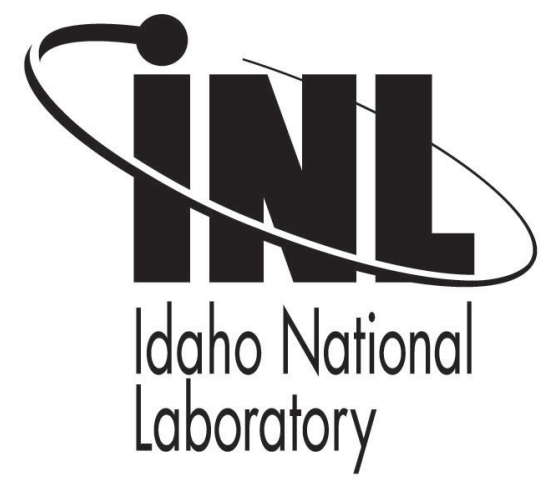

This is a preprint of a paper intended for publication in a journal or proceedings. Since changes may be made before publication, this preprint should not be cited or reproduced without permission of the author. This document was prepared as an account of work sponsored by an agency of the United States Government. Neither the United States Government nor any agency thereof, or any of their employees, makes any warranty, expressed or implied, or assumes any legal liability or responsibility for any third party's use, or the results of such use, of any information, apparatus, product or process disclosed in this report, or represents that its use by such third party would not infringe privately owned rights. The views expressed in this paper are not necessarily those of the United States Government or the sponsoring agency. 


\section{ELECTRICAL POWER GRID DELIVERY DYNAMIC ANALYSIS: USING PRIME MOVER ENGINES TO BALANCE DYNAMIC WIND TURBINE OUTPUT}

\author{
Diana K. Grauer, PhD \\ Idaho National Laboratory \\ Idaho Falls, Idaho, USA
}

\author{
Michael E. Reed \\ Idaho National Laboratory \\ Idaho Falls, Idaho, USA
}

\begin{abstract}
This paper presents an investigation into integrated wind + combustion engine high penetration electrical generation systems. Renewable generation systems are now a reality of electrical transmission. Unfortunately, many of these renewable energy supplies are stochastic and highly dynamic. Conversely, the existing national grid has been designed for steady state operation. The research team has developed an algorithm to investigate the feasibility and relative capability of a reciprocating internal combustion engine to directly integrate with wind generation in a tightly coupled Hybrid Energy System. Utilizing the Idaho National Laboratory developed Phoenix Model Integration Platform, the research team has coupled demand data with wind turbine generation data and the Aspen Custom Modeler reciprocating engine electrical generator model to investigate the capability of reciprocating engine electrical generation to balance stochastic renewable energy.
\end{abstract}

\section{INTRODUCTION}

As global population climbs toward an expected 8 billion people by 2030 , primary energy consumption is expected to increase by almost $40 \%$ from approximately 520 exajoules consumed today to almost 740 exajoules [1][2]. Energy used for transportation, industrial, commercial, and residential energy use is expected to grow substantially creating considerable pressure on global and local energy markets. The size and timing of growth in energy use is expected to cause the world's governments to implement policy and energy infrastructure based on balancing the three pillars of energy security: economic stability, environmental sustainability, and resource security [3].

Clean energy resources such as nuclear, solar, hydropower, and wind have the potential to satisfy part of the growing energy demands, even as global use of fossil energy, particularly coal, continues to rise [1][2]. However, fully leveraging these clean energy resources will require new technology and energy system approaches to fully integrate these resources into energy markets beyond electricity (industrial processes and transportation). In addition, more efficient and effective electricity production and transmission systems will need to be developed. These electricity systems will need to mitigate the impact of intermittency created by integration of major renewable energy resources (wind and solar), and avoid mismatches between load and generation created by integration of large generation sources (nuclear and/or coal) in constrained electricity markets. Intermittency and production/demand mismatch could cause inefficient capital use and/or system instability.

One approach to meeting these objectives is hybrid energy systems (HES). Broadly described, HES are energy product production plants that take two or more energy resource inputs (typically includes both carbon and non-carbon based sources) and have the capability to produce multiple energy products (e.g. electricity, liquid transportation fuels, industrial chemicals) in an integrated plant. Studies have shown that nonnuclear integrated (hybrid) energy systems can have appealing attributes in terms of overall process efficiency [4], enhanced electric grid stability, renewable energy integration, economic performance [5][6][7], and lifecycle greenhouse gas emissions [8].

\section{ENERGY MANAGEMENT}

The Department of Energy (DOE) Federal Energy Management Program (FEMP) facilitates the Federal Government's implementation of sound, cost-effective energy management and investment practices to enhance the nation's energy security and environmental stewardship [9]. Federal agencies must meet energy management requirements outlined by each of the following Federal statutory laws and regulations:

- National Energy Conservation Policy Act

- Executive Order (EO) 13514 
- $\quad$ Energy Independence and Security Act of 2007

- EO 13423

- Energy Policy Act of 2005

- EO 13221

- Energy Policy Act of 1992

Each of the listed Federal statutory laws and regulations require all Federal agencies to meet a variety of energy management requirements, for example: renewable energy use increase, greenhouse gas management, petroleum use reduction and alternative fuel use increase, etc. For example, EO 13423 mandates that at least half of renewable energy used by the Federal Government must come from new renewable sources (in service after January 1, 1999), spurring the continued installation of renewable sources of energy generation [9].

Parallel to implementation of the various FEMP mandates, the Under Secretary of Defense for Acquisition, Logistics and Technology commissioned a Defense Science Board Task Force on Department of Defense (DOD) Energy Strategy. The Task Force concluded that:

Almost complete dependence of military installations on a fragile and vulnerable commercial power grid and other critical national infrastructure places critical military and Homeland defense missions at an unacceptably high risk of extended disruption [10].

The Task Force recommended that DOD:

Reduce the risk to critical missions at fixed installations from loss of commercial power and other critical national infrastructure. The DOD should take immediate actions to "island" the installations and increase the efficiency of critical equipment to reduce the burden for backup systems [10].

Subsequently, the Army, through the Energy Security Implementation Strategy set five long-term energy security goals:

1. Reduced energy consumption;

2. Increased energy efficiency across platforms and facilities;

3. Increased use of renewable/alternative energy;

4. Assured access to sufficient energy supplies; and

5. Reduced adverse impacts on the environment.

Therefore, the research team has focused this work on investigating the feasibility of "islanding" a single military installation with the wind resources to install a $30 \mathrm{MW}$ windgeneration facility. The work examines a small, tightly coupled wind + combustion engine, high penetration electrical generation system to supply secure, sustainable electricity to a military installation. It is assumed that the installation electrical distribution system can be modified to allow for fast configuration between standard (on-grid) and utilityindependent ("islanded") operation.

\section{RENEWABLE ENERGY GENERATION}

The electricity grid is designed to address two fundamental facts. First, the electrical loads that the system must meet can vary over each minute, hour and season by $50 \%$ or more.
Second, each generation type has different operating characteristics, both positive and negative.

Fossil and nuclear plants generally provide stable "baseload generation," but those plants can fail suddenly or require unscheduled maintenance, so the grid always needs back-up reserves. Coal and nuclear plants are also relatively inflexible resources - they cannot be ramped up and down economically to follow hourly load swings. Therefore, the grid requires large amounts of quickly rampable resources like natural gas plants and some hydro generation to handle swings in load in addition to baseload power [11].

Wind projects, on the other hand, produce output that is difficult to predict more than a few hours ahead of time and can be controlled only in the down direction. Blades can be "feathered" to reduce their output, and newer wind plants restrain how fast they ramp up when the wind starts to blow. These mechanisms can help the grid deal with rapid increases in wind, but not with down ramps - or of course with no wind at all.

To match load and generation, grid operators rely on flexible or "dispatchable" resources, usually gas-fired turbines or reciprocating internal combustion engines (RICE), and hydropower. Every system has in place today enough of these resources to match loads with resources through hourly, daily and seasonal changes plus extra reserves to cover unexpected outages. Adding wind to the grid requires more of these dispatchable resources [11].

A May, 2010 report by the National Renewable Energy Laboratory (NREL) entitled the "Western Wind and Solar Integration Study", investigated the operational impact of a $30 \%$ wind plus $5 \%$ solar energy penetration on the grid served by the WestConnect utilities. These utilities cover the states of Nevada, Colorado, Wyoming, Arizona and New Mexico. Its main conclusion was:

It is feasible for the WestConnect region to accommodate $30 \%$ wind and $5 \%$ solar energy penetration. This requires key changes to current practice, including substantial balancing area cooperation, sub-hourly scheduling, and access to underutilized transmission capacity [12].

While the study showed that integration of large amounts of renewables was feasible and economical, it requires the following changes to current practices:

1. Substantially increase balancing area cooperation or consolidation, real or virtual;

2. Increase the use of sub-hourly scheduling for generation and interchanges;

3. Increase utilization of transmission;

4. Enable coordinated commitment and economic dispatch of generation over wider regions;

5. Incorporate state-of-the-art wind and solar forecasts in unit commitment and grid operations; and

6. Increase the flexibility of dispatchable generation where appropriate (e.g., reduce minimum generation levels, increase ramp rates, reduce start/stop costs or minimum down time) [12]. 
Highlighting item number six of the preceding list, it is apparent that this issue can be addressed via the use of large reciprocating engine generation plants. The integration of reciprocating engine with renewable resources may provide the needed stability for growth in the use of renewable based power generation.

\section{INTEGRATION CHALLENGES}

Wind turbine electrical generation is not only "nondispatchable," meaning that it is not rampable, but is stochastic and highly dynamic, shown in Figure 1.

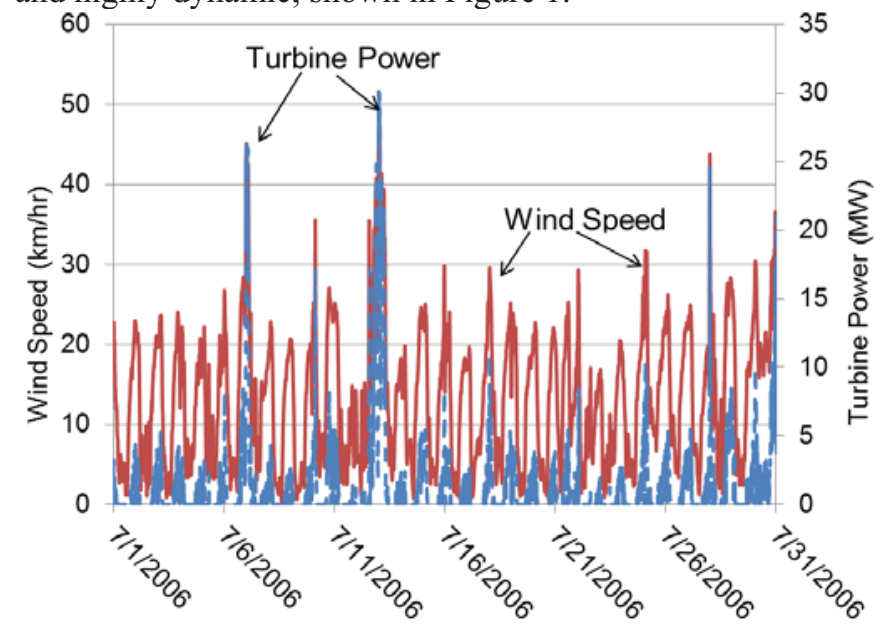

Figure 1: Example of July Wind Speed and Generation

Figure 1 highlights not only the highly stochastic nature of wind itself, but shows how relatively "unavailable" wind generation is during the summer months when electrical demand is generally at its highest for the locality identified for this study. This wind farm was rated at 30 megawatts (MW); note that the average generation for the month of July was approximately $1.54 \mathrm{MW}$. Also of note is that the daily electrical generation peaks happen around 2:00 AM, when demand is at its lowest [12].

There are a variety of methods by which wind energy and its transfer to the electrical grid is characterized:

- Capacity factor - the ratio of the actual energy produced in a given period, to the hypothetical maximum possible, i.e. running full time at rated power.

- Penetration - amount of energy produced by a resource, as a percentage of total energy used, in a given region.

- Dispatchability - ability of a power plant to be turned on quickly to a desired level of output.

For comparison, approximate ranges of values of each are shown in Table 1.

Table 1: Comparison of Wind Energy [12]

\begin{tabular}{|l|l|l|l|l|l|l|}
\hline & \multicolumn{2}{|l|}{ Wind } & \multicolumn{2}{l|}{ RICE } & \multicolumn{2}{l|}{ Baseload } \\
\cline { 2 - 6 } & Max & Min & Max & Min & Max & Min \\
\hline
\end{tabular}

\begin{tabular}{|l|l|l|l|l|l|l|}
\hline Capacity Factor & 40 & 20 & 80 & 60 & 90 & 70 \\
\hline Penetration & $20 \%$ & $5 \%$ & $40 \%$ & $20 \%$ & $60 \%$ & $40 \%$ \\
\hline Dispatchability & NA & NA & $90 \%$ & $80 \%$ & $60 \%$ & $40 \%$ \\
\hline
\end{tabular}

Large reciprocating internal combustion engine powered electrical generation has the capability to provide energy solutions for the integration of intermittent renewable generation sources, i.e. wind. Previously, this pairing of RICE and wind has been limited to separate generation sources located "near" each other on the local or regional electrical grid, shown in Figure 2. The RICE was then used as backup for the wind farm during periods of high demand.

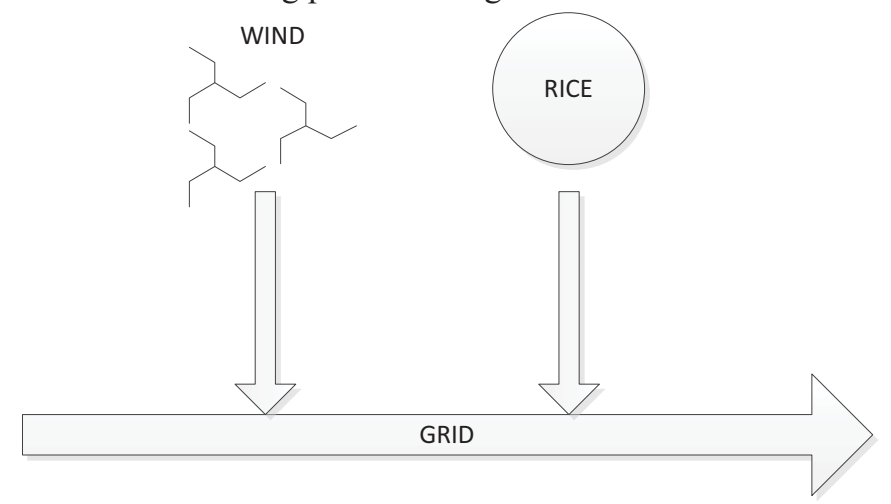

Figure 2: Conventional Energy Integration

Alternately, this paper investigates the feasibility and relative capability of the RICE to directly integrate with wind generation in a tightly coupled Hybrid Energy System, shown in Figure 3.

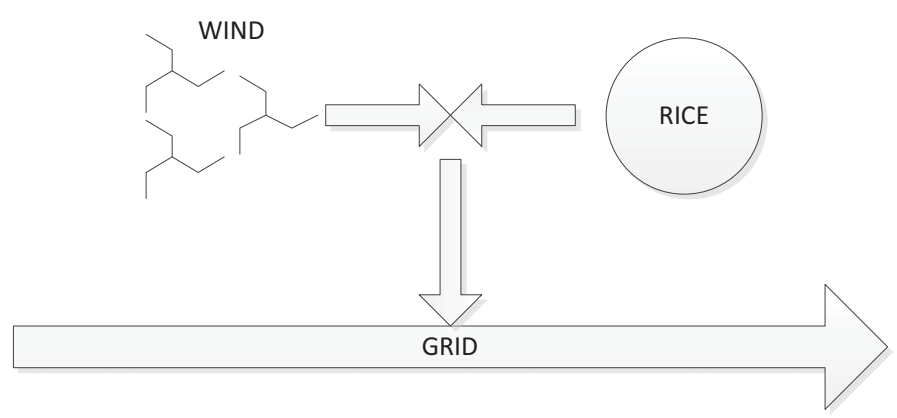

Figure 3: Tightly Coupled Energy Integration

\section{INTEGRATED MODEL}

The goal of the tightly coupled energy integration development was to investigate the feasibility, challenges, and technology development required to truly increase the capacity factor, penetration, and dispatchability of a wind-RICE Hybrid Energy System.

Using the local demand and wind turbine operating data, the authors determined the daily generation requirement, and associated ramp rates required to effectively dispatch the RICE generation system. 
The model integration architecture, shown in Figure 4 utilized local demand data to develop an algorithm for required electrical generation. This electrical generation was then compared with available wind generation, triggering the dynamic RICE algorithm to meet any electrical generation requirements not met by the stochastic nature of the wind.

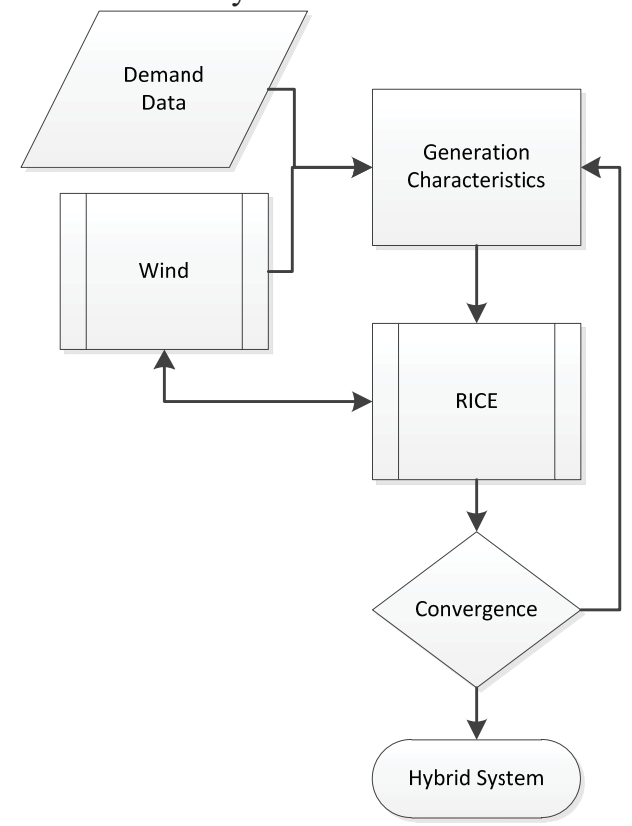

Figure 4: Model Integration Architecture

The wind turbine sub-model was based on simulations of wind generation extracted from the NREL Western Wind Dataset. The dataset was created using Numerical Weather Prediction models that recreated historical weather for the western US. The modeled data was temporally sampled every 10 minutes and spatially sampled every arc-minute (approximately 2 kilometers) [12]. The NREL dataset allowed the research team to develop a control based algorithm to quantify date- and site-specific wind turbine operation. The control based wind turbine sub-model was then wrapped and integrated into the Phoenix Model Integration Platform.

Parallel to the wind turbine sub-model, the research team developed a temporally based mean-value reciprocating engine model. The thermodynamic RICE algorithm includes: 1) first and second law thermodynamic model for air delivery and exhaust removal, 2) mass and energy balances, using equations of state and chemical equilibrium, for in-cylinder pressure and temperature, and 3) chemical kinetic models for pollutant emission formation. This thermodynamic algorithm is then encapsulated by a control based model that effectively translates in-cylinder pressure into mechanical work. RICE mechanical shaft work is then translated to electrical generation via an electrical generator model. The data flow resulting in the completed dynamic RICE algorithm for electrical generation is shown in Figure 5.

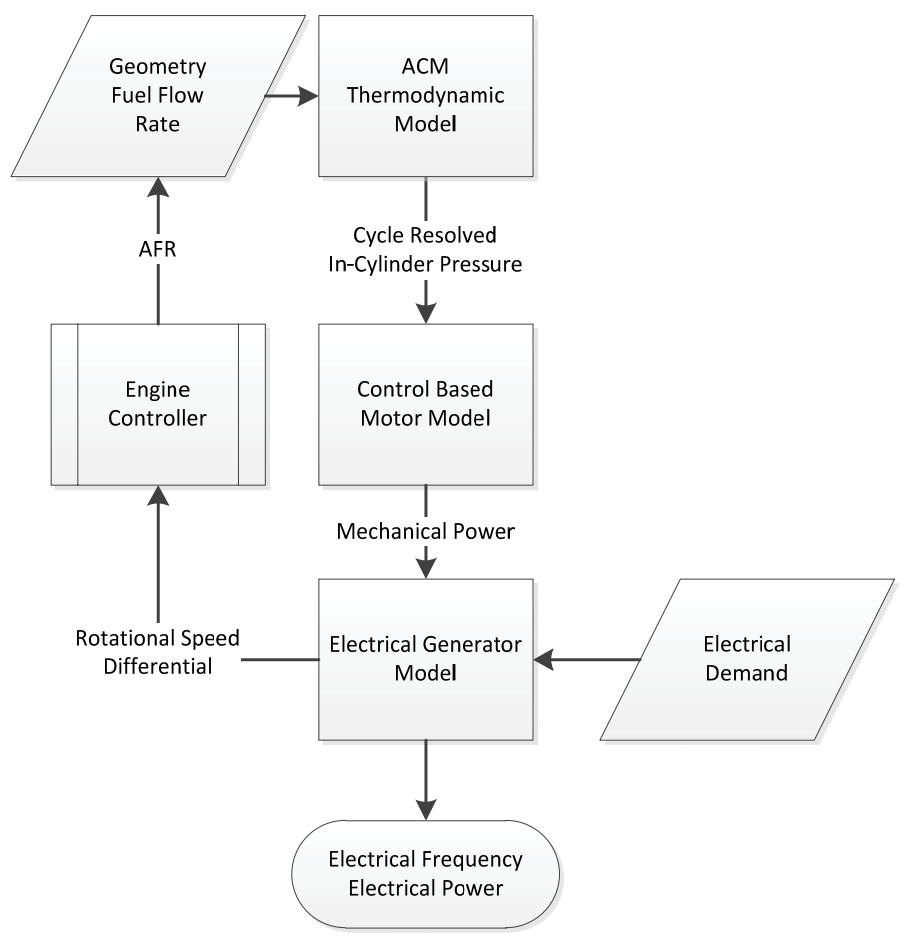

Figure 5: Dynamic RICE Algorithm

As the dynamic RICE algorithm operated in response to both demand and wind generation changes, it became apparent to the research team, that existing RICE may not be capable of such dynamic operation. The wind-RICE hybrid system requires multiple megawatt output ramping over relatively short spans of time. For example, in order to operate without over or under producing to avoid waiting fuel or risking an electrical brown-out of the area, the prime mover would have to effectively fill in the gap in generation between the wind and demand lines as shown in .

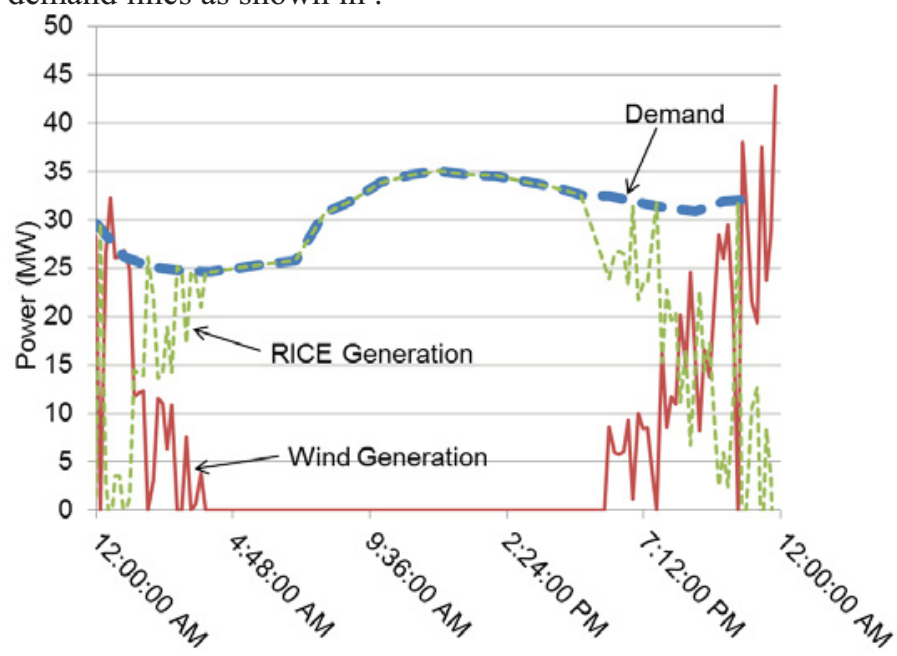

Figure 6: RICE Intermittent Generation Requirement

This dynamic operation raises important questions as to the capability of large industrial engines to operate as intermittent 
and load following generation sources. In response to these operational questions, the authors collected data about existing RICE ramp rates. On average, large reciprocating engines are capable of ramp rates (load and unload) of $30 \mathrm{~kW} / \mathrm{s}(1.8$ $\mathrm{MW} / \mathrm{min})$ [13].

In order to investigate the feasibility of operating the windRICE HES, the research team mapped the required electrical generation of the RICE versus the required ramp rate to balance the wind turbine generation ().

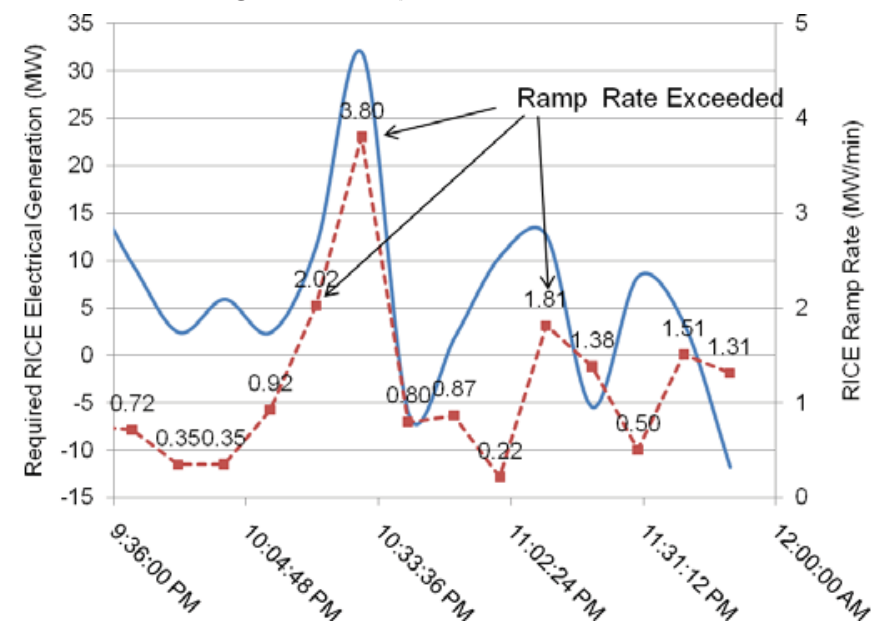

Figure 7: RICE Generation and Required Ramp Rate

highlights two opportunities for further investigation into the operation of a wind-RICE HES:

1. Ramp rate exceeded: at three different 10 minute intervals (beginning at 10:20 PM, 10:30 PM, and $11: 10 \mathrm{PM}$ ) the maximum ramp rate of $1.8 \mathrm{MW} / \mathrm{min}$ is exceeded. Either tighter control of the RICE is needed to facilitate higher ramp rates, or some other mechanism for electrical generation must be integrated (e.g. battery).

2. "Negative" RICE electrical generation values: at 10:40 $\mathrm{PM}$, 11:20 PM, and 11:50 PM, the wind generation is in excess of the electrical demand. Therefore, the RICE is not needed, but some form of dynamic electrical storage is needed.

Furthermore, the wind-RICE HES algorithm assumes that advanced automation and control of intelligent plant devices integrated into some mechanism for plant-wide communication is available. A brief review of available literature suggests that this level of automation, control, and integration may not be currently available for implementation [1][4][6][7][14][15].

\section{SEASONAL ANALYSIS}

In order to effectively characterize seasonal variations in potential wind generation and therefore, the required windRICE HES, the research team analyzed one year of transient electrical demand, collected hourly. The demand was then used as a forcing function for the wind + RICE integrated model.
The research team divided the year into four seasons and selected four representative months for this work: January, April, July, and October.

The relationship between required electrical generation (demand) and wind turbine electrical power is shown for the month of January in Figure 8. Wind generation is relatively "available" during the winter months as the wind turbines are generating more than $50 \%$ ( $15 \mathrm{MW}$ ) of the plant rated power approximately $62 \%$ of the month. In addition to the wind generation facility, another $17 \mathrm{MW}$ of peaking electrical generation is needed to satisfy the installation demand (Figure $8)$.

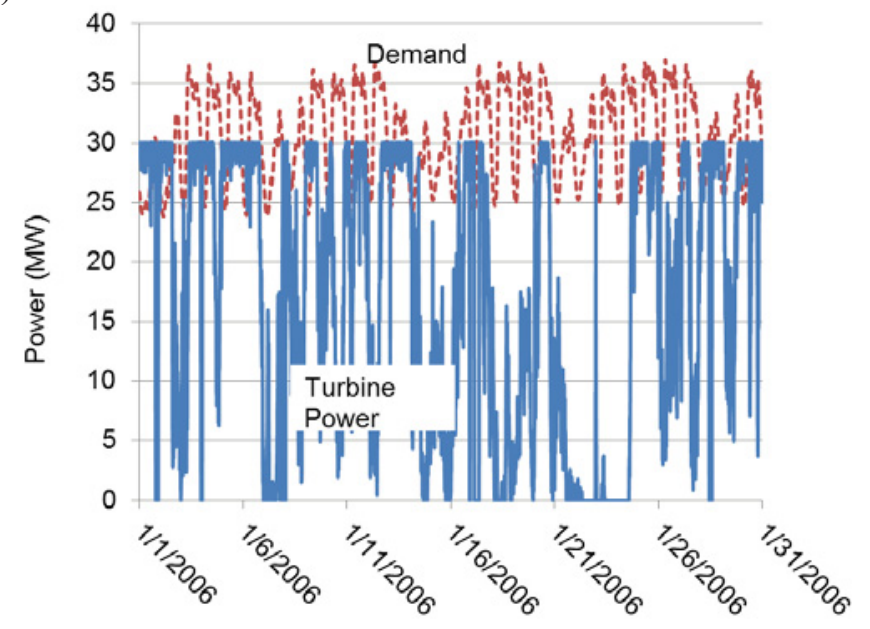

Figure 8: January Demand and Available Turbine Power

Each month is presented (Table 2) in terms of:

1. Maximum and minimum values of electrical generation from the wind generation facility and the required supplemental generation from RICE to meet the installation electrical demand.

2. Plant capacity factor and electrical penetration (as defined earlier).

3. Maximum required ramp rate of the RICE in order to effectively "chase" and balance deficits in wind turbine generation.

Table 2 highlights the need for at least $36 \mathrm{MW}$ of installed RICE generation during the month of January, in order to effectively "chase" the $30 \mathrm{MW}$ wind turbine field to supply an uninterrupted $35.93 \mathrm{MW}$ of power to the installation (maximum demand for January). Note that the capacity factor for the RICE supplement in Table 2 is significantly lower than the ranges of values reported in Table 1 (80-60). This is due to curtailment of the output because the electricity is not needed due to the availability of wind turbine generation. Unfortunately, during this period, the maximum ramp rate required of the RICE to respond to the wind turbine variability is well above the equipment limit of $1.8 \mathrm{MW} / \mathrm{min}$. Also, given that only electrical sources evaluated during this study were the coupled wind turbine field and RICE facilities, the electrical penetration values will sum to $100 \%$. 
Table 2: Summary of January Operation

\begin{tabular}{|l|l|l|}
\hline JANUARY & $\begin{array}{l}\text { Available (Rated) } \\
\text { Turbine Power }\end{array}$ & $\begin{array}{l}\text { Required RICE } \\
\text { Supplement }\end{array}$ \\
\hline Maximum (MW) & 30 & 35.93 \\
\hline Minimum (MW) & 0 & 23.83 \\
\hline Capacity Factor & 17.86 & 11.15 \\
\hline Penetration (\%) & 56.52 & 43.48 \\
\hline $\begin{array}{l}\text { Maximum Ramp } \\
\text { Rate (MW/min) }\end{array}$ & NA & 2.81 \\
\hline
\end{tabular}

During the first half of the month of April, Figure 9 shows that wind power is available more than $50 \%$ of the time. This availability effectively drops off toward the end of the month.

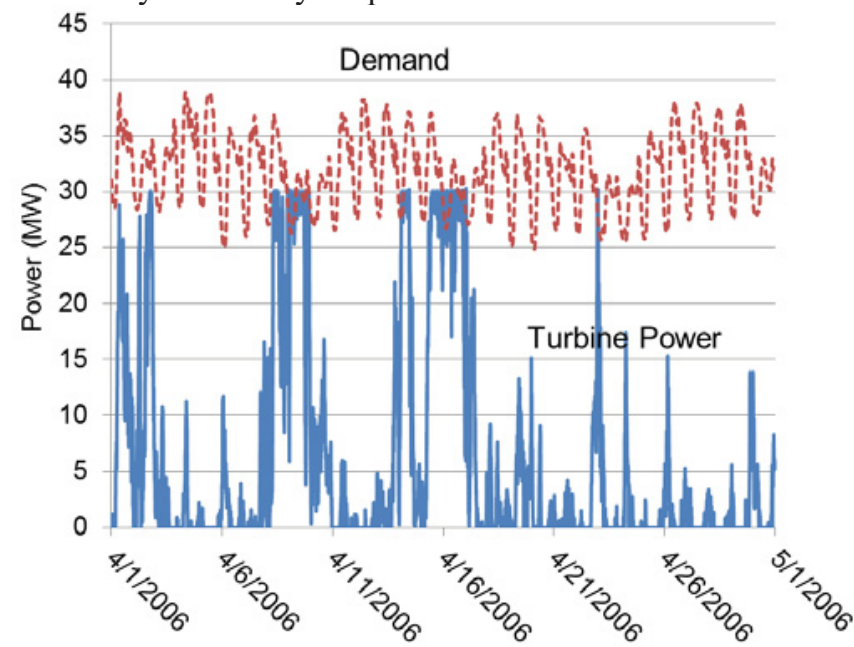

Figure 9: April Demand and Turbine Electrical Power

Data for April (Table 3) reveals an increase in the required size of RICE generation due directly to an increase in demand. Additionally, the wind power capacity factor decreases, as the RICE factor increases to compensate. This compensation is also shown in the variation in electrical penetration values. Again, the RICE is unable to react quickly enough to variations in the wind turbine generation.

Table 3: Summary of April Operation

\begin{tabular}{|l|l|l|}
\hline APRIL & $\begin{array}{l}\text { Available (Rated) } \\
\text { Turbine Power }\end{array}$ & $\begin{array}{l}\text { Required RICE } \\
\text { Supplement }\end{array}$ \\
\hline Maximum (MW) & 30 & 38.85 \\
\hline Minimum (MW) & 0 & 24.88 \\
\hline Capacity Factor & 6.02 & 19.89 \\
\hline Penetration (\%) & 18.93 & 81.06 \\
\hline $\begin{array}{l}\text { Maximum Ramp } \\
\text { Rate (MW/min) }\end{array}$ & NA & 2.08 \\
\hline
\end{tabular}

As previously discussed (Figure 1), wind power is relatively "unavailable" during the summer months when electrical demand is generally at its highest for the locality identified for this study. The maximum installation demand is 39.85 MW on July $11^{\text {th }}$, at which time wind generation is minimal.

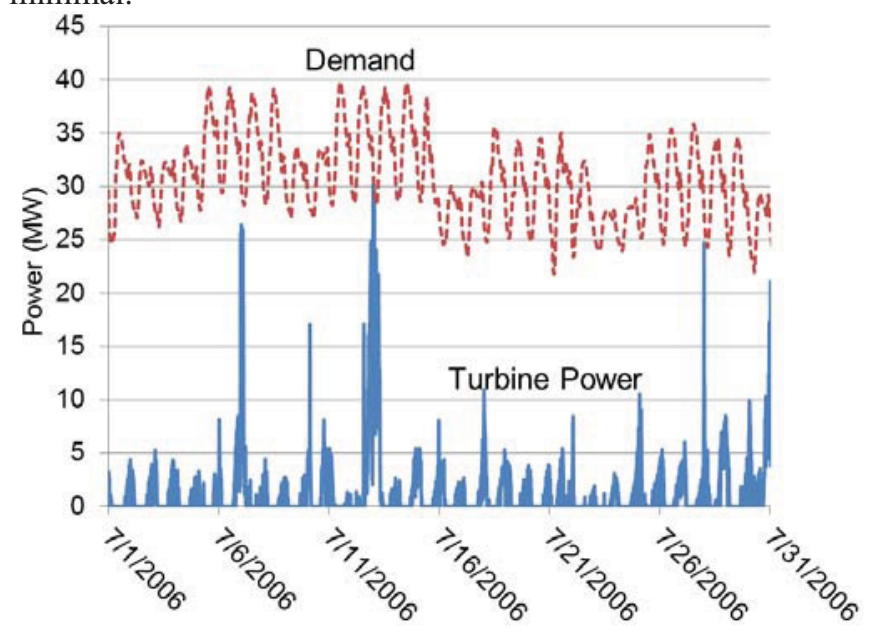

Figure 10: July Demand and Available Turbine Power

From April to July, the RICE requirement stays effectively the same (Table 4). Generation from the wind field falls off such that both the capacity factor and penetration values are below the generalized ranges reported in Table 1. Note that the required penetration of the RICE is well above the range previously reported in this work. Therefore, in order to ensure continuous generation during the summer months, spinning reserve and backup RICE must be sized accordingly, and regular maintenance must also be scheduled to accommodate the required demand.

\section{Table 4: Summary of July Operation}

\begin{tabular}{|l|l|l|}
\hline JULY & $\begin{array}{l}\text { Available (Rated) } \\
\text { Turbine Power }\end{array}$ & $\begin{array}{l}\text { Required RICE } \\
\text { Supplement }\end{array}$ \\
\hline Maximum (MW) & 30 & 38.72 \\
\hline Minimum (MW) & 0 & 21.57 \\
\hline Capacity Factor & 1.58 & 23.29 \\
\hline Penetration (\%) & 5.01 & 94.99 \\
\hline $\begin{array}{l}\text { Maximum Ramp } \\
\text { Rate (MW/min) }\end{array}$ & NA & 3.80 \\
\hline
\end{tabular}

In contrast to the April data, Figure 11 shows that wind power is available almost $50 \%$ of the time during the last half of the month. The availability of wind power steadily increases in this region during the fall, peaking in the winter. Compared to July data (Figure 10), the demand for electrical power has also decreased. 


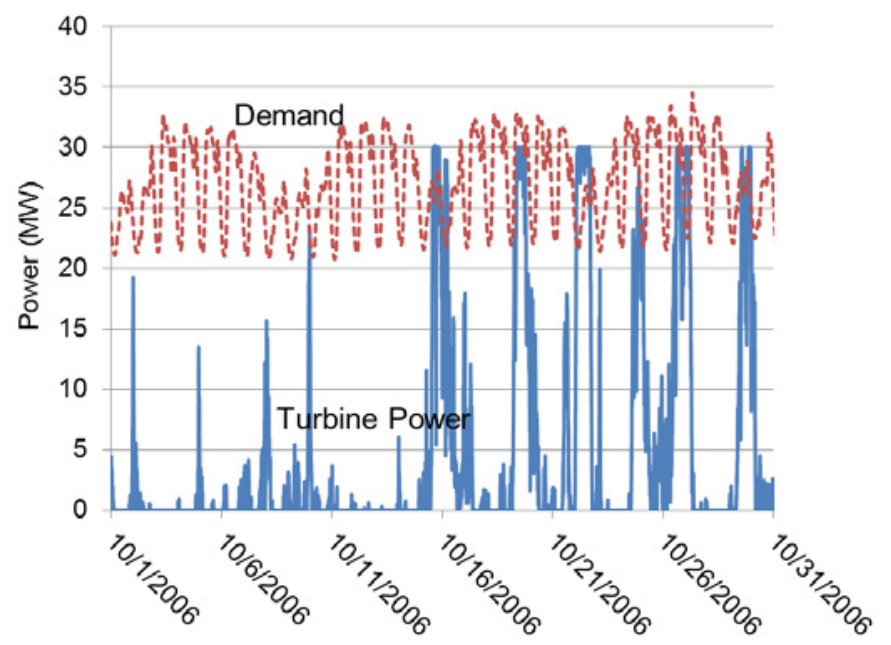

Figure 11: October Demand and Turbine Electrical Power

As expected for this locality, October values for both capacity factor and electrical penetration (Table 5) are similar to those for April (Table 3) and significantly lower than those for January (Table 2).

Table 5: Summary of October Operation

\begin{tabular}{|l|l|l|}
\hline OCTOBER & $\begin{array}{l}\text { Available (Rated) } \\
\text { Turbine Power }\end{array}$ & $\begin{array}{l}\text { Required RICE } \\
\text { Supplement }\end{array}$ \\
\hline Maximum (MW) & 30 & 31.61 \\
\hline Minimum (MW) & 0 & 20.76 \\
\hline Capacity Factor & 4.46 & 22.25 \\
\hline Penetration (\%) & 15.98 & 84.02 \\
\hline $\begin{array}{l}\text { Maximum Ramp } \\
\text { Rate (MW/min) }\end{array}$ & NA & 2.65 \\
\hline
\end{tabular}

The authors plan to continue to develop this integrated model to investigate further opportunities, constraints, and control requirements for dynamic operation of RICE.

\section{CONCLUSION}

In conclusion, the research team has developed an algorithm for instantaneous electrical penetration to investigate the feasibility and relative capability of the RICE to directly integrate with wind generation in a tightly coupled Hybrid Energy System.

This study identifies both the need for more tightly electrical storage. This development will lead to control development for reactive power needs and eventually include work in voltage and frequency regulation. The investigators plan to expand the tightly coupled energy integration model to include other stochastic, non-dispatchable sources of renewable energy.
NOMENCLATURE

\begin{tabular}{|l|l|}
\hline DOE & Department of Energy \\
\hline DOD & Department of Defense \\
\hline EO & Executive Order \\
\hline FEMP & Federal Energy Management Program \\
\hline HES & Hybrid Energy System \\
\hline INL & Idaho National Laboratory \\
\hline NREL & National Renewable Energy Laboratory \\
\hline RICE & Reciprocating Internal Combustion Engine \\
\hline
\end{tabular}

\section{REFERENCES}

[1] World Nuclear Association 2010 (www.world-nuclear.org)

[2] International Energy Outlook 2009, U.S. Energy

Information Administration (www.eia.doe.gov/ieo/world.html)

[3] Aumeier, S.E., et al, Carbon Management, Energy Security, and the Future of Nuclear Energy, Presentation at Energy Futures, University of Washington (http://courses.washington,edu/efuture/) (May 2010)

[4] Ruixian, C. et al., Development of Multifunctional Energy Systems (MESs), Energy, 2009, (1-8)

[5] Phadke, A. et al., Advanced Coal Wind Hybrid: Economic Analysis, E.O. Lawrence Berkeley National Laboratory Report - LBNL-1248E (2008)

[6] Hemmes, K. et al., Towards multi-source Multi-Product Energy Systems, International Journal of Hydrogen Energy, 2007, 32, (1332-1338)

[7] Yamashita, K. and Barreto, L., Integrated Energy Sytems for the $21^{\text {st }}$ Century: Goal Gasification for Co-producing Hydrogen, Electricity and Liquid Fuels, International Institute for Applied Systems Analysis, Interim Report IR03-039

[8] Larson, E.D. et al., Co-production of Decarbonized Synfuels and Electricy from Coal+Biomass with $\mathrm{CO} 2$ Capture and Storage: An Illinois Case Study, Energy and Env. Science, 2010, 3, (28-42)

[9] Federal Energy Management Program, 2011, (www1.eere.energy.gov/femp/)

[10] "More Fight - Less Fuel," Report of the Defense Science Board Task Force on DOD Energy Strategy, February 2008

[11] Idaho Baseload Taskforce, 2011 Report, Idaho Strategic Energy Aliance, 2011

[12] Western Wind and Solar Integration Study, NREL, May 2010, pages 3-27

[13] Wagar, A.N., Wartsila Power Plants, April 23, 2008

[14] Wagar, N. et al., flexible Power with Reciprocating Gas Engines, Powergen Europe, June 7-9, 2011.

[15] Seeling-Hochmuth, G. Optimization of Hybrid Energy Systems: Sizing and Control, Dissertation, University of Kassel, 1998 